\title{
Measurement Analysis in Electrochemical Discharge Machining (ECDM) Process: A Literature Review
}

\author{
Pravin Pawar ${ }^{1}$, Raj Ballav ${ }^{2}$ and Amaresh Kumar ${ }^{3}$ \\ Department of Manufacturing Engineering, National Institute of Technology, Jamshedpur 831014, India
}

\begin{abstract}
Electrochemical discharge machining is considered to be a hybrid machining process that combines with EDM and ECM (electro chemical machining), called ECDM. The material removal is based on two phenomena: electrochemical dissolution of the material and thermal erosion of electrical discharges that occur between the cathode $\&$ anode electrodes. This process is better used for machining of non conducting materials efficiently. In this research paper shows that a brief literature review study of various measuring instruments used for analysis of various parameters of the electrochemical discharge machining process on various types of materials, tool material, input \& output parameters such as surface roughness, surface texture, material removal, tool wear etc.
\end{abstract}

Key words: ECDM, SEM (scanning electron microscope), oscilloscope.

\section{Introduction}

Measuring tools used in ECDM (electrochemical discharge machining) machining process such as SEM (scanning electron microscope), optical microscope, AFM (atomic force microscope), Oscilloscope, pyrometer for measuring parameters of micro components such as surface roughness, surface texture, current voltage waveforms, temperature etc.

\section{SEM (Scanning Electron Microscope)}

One of the primary tools used for analysis of micro \& nano images is SEM. A electron microscope in which the surface of a specimen is scanned by a beam of electrons that are reflected to form an image.

\subsection{Creator \& Debris}

J. W. Liu et al. has studied for ECDM machining used to machine MMC (metal matrix composites) material Craters \& debris produced in the processing condition emulsion medium was used and the spark gap size was $5 \mathrm{~mm}$. Materials are found out of magnification was $\mathrm{X} 100 \&$ area $100 \mu \mathrm{m}$ as shown in Fig. 1 [1].

\footnotetext{
*Corresponding author: Pravin Pawar, Ph.D., research filed: manufacturing engineering. E-mail: 2013rsprod004@nitjsr.ac.in.
}

\subsection{Micro Hole}

A. Ravi Sankar et al. analyzed Circular hole micro-machined using the $45 \% \mathrm{NaOH}$ solution as an electrolyte micro-machined hole is around $450 \mu \mathrm{m}$. Magnification X60 \& Area of $200 \mu \mathrm{m}$ [2]. Margareta Coteața et al. also produced micro hole measured using (SEM) (Hitachi S-4800) top side hole and sectional view of the hole taking X120 $400 \mu \mathrm{m}$ as shown in Fig. 2 [3].

\subsection{Tool Wear}

Margareta Coteața et al. measured wear of the electrode tool using SEM obtained magnification of $\mathrm{X} 300 \&$ area of $100 \mu \mathrm{m}$ as shown in Fig. 3 [3]. Cheng-Kuang Yang measured Geometrical dimensions of micro-tool electrodes micro-holes machined by different tool electrodes, different machining depth and cross-section profile of through holes [4]. C. T. Yang et al. found out using SEM micrographs of slit given different wire tensions $4 \&$ $8 \mathrm{~N}$ at different abrasive concentrations pure electrolyte, concentration $100 \mathrm{~g} / \mathrm{L} \& 300 \mathrm{~g} / \mathrm{L}$, surface at different power frequencies 40, 67 and $100 \mathrm{~Hz}$ [5]. 


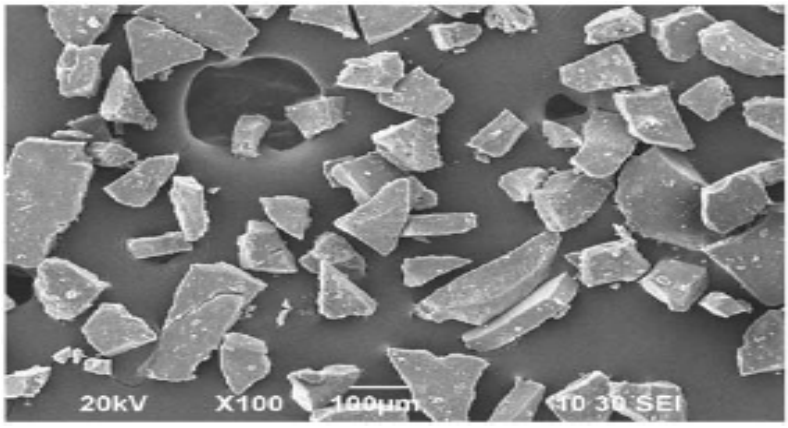

Fig. 1 Large debris particles ECDM process.

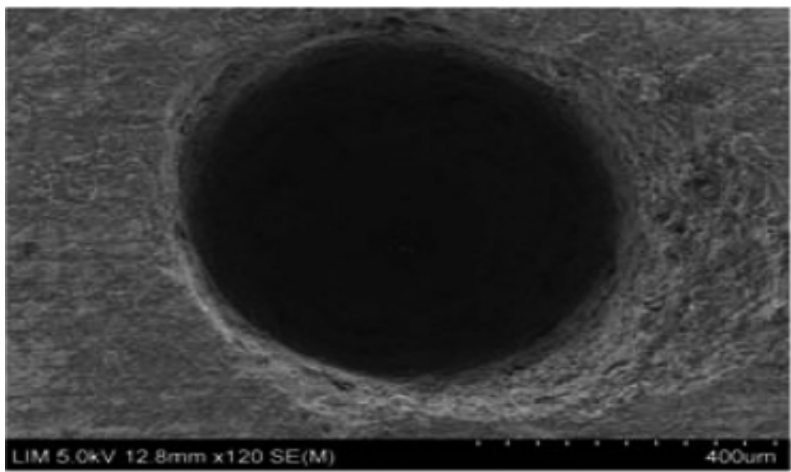

Fig. 2 Image of top side machined hole.

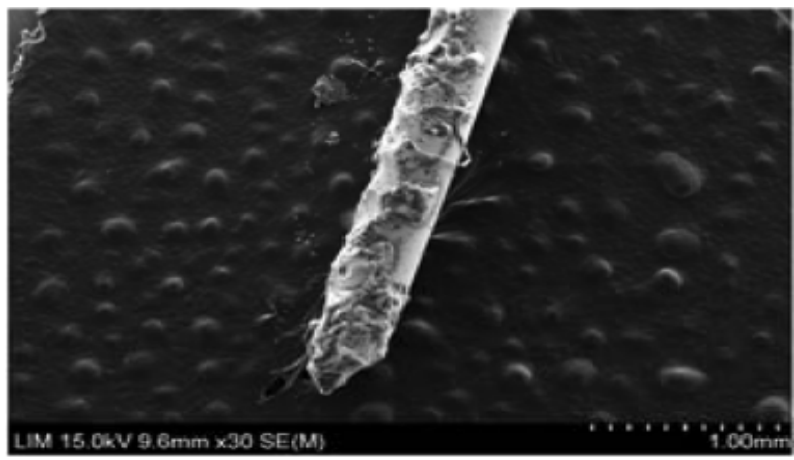

Fig. 3 Wear of the electrode tool.

\subsection{Micro Channel}

V. K. Jain et al. measured micro channel using SEM image of micro-machined channel depth of $1,348.07 \mu \mathrm{m}$, width of $643.41 \mu \mathrm{m}$, aspect ratio of 2.1 , Fig. 4 shows that shadowgraph sketch of a micro-channel and heat affected zone [6].

\subsection{Micro Groove}

Zhi-Ping Zheng et al. have produced a machined microgroove in a Pyrex glass with a cylindrical tool of $200 \mu \mathrm{m}$ diameter. Using SEM found out the surface structure of the machining area of micro groove shown in Fig. 5 [7].

\subsection{Grinding Effect of ECDM}

J. W. Liu et al. have measured grinding effect of ECDM. In that machined surfaces a with grinding effect under a single pulse processing condition parameters are such as electrolyte concentration 2.5 $\mathrm{w} \%$, applied voltage $90 \mathrm{~V}$, pulse duration $200 \mu$ s, duty cycle 1:7, spindle speed 15,000 RPM \& workpiece material was taken as $10 \mathrm{AlO}$ composite, $10 \mathrm{AlO}$ and 20 AlO. The SEM micrographs show the crater distribution on the MMC surfaces after by G-ECDM as shown in Fig. 6 [8].

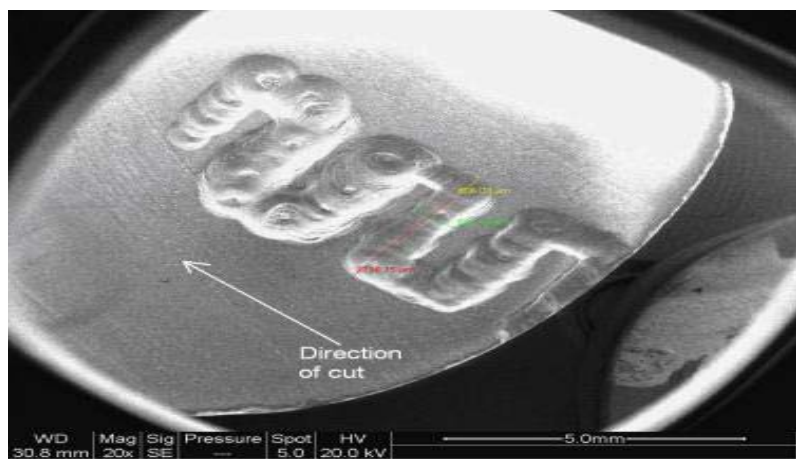

Fig. 4 SEM photograph of the micro channel.

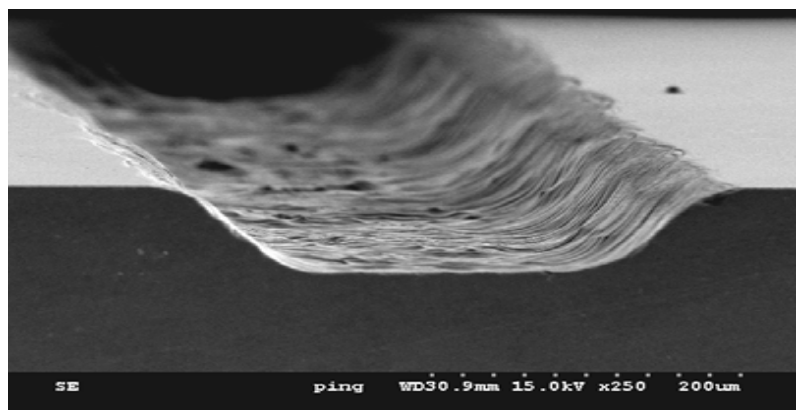

Fig. 5 Machined microgroove in a Pyrex glass.

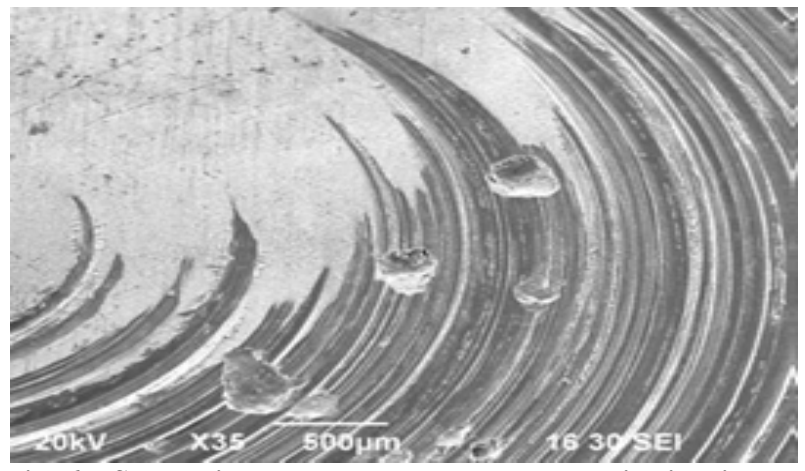

Fig. 6 SEM micrograph showed the crater distribution on the MMC surface after an G-ECDM. 


\section{XRD Analyser}

J. W. Liu et al. used XRD Analyser for analysis of the phases of the EDM and ECDM specimens shown in Fig. 7 [1].

\section{Oscilloscope}

J.W. Liu et al. used oscilloscope for measurement of ECDM machined affecting various parameters such as current, duty cycle, pulse duration, electrolyte concentration [1]. M. Schopf et al. found out ECM phases have to be combined with EDM phases. Using oscilloscope measured voltage and current waveforms during ECDM process is shown in Fig. 8 [9]. V. Raghuram et al. have also used oscilloscope for analyzing the average current and voltage were recorded on a potentiometric strip chart recorder with the help of a calibrated resistance network. For that purpose oscilloscope (DSS 2011 Kikusui, Japan) \& Ocillograpic Recorder (8801 Hioki, Japan) were used [10]. Anjali V. Kulkarni has developed the concept of measurement of ECDM process parameters such that synchronised time-varying current and temperature for the copper work piece. For analysis of Pyrometer temperature transients and current transients are measured and stored using KIKUSUI $60 \mathrm{MHz}, 4$ channel digital storage oscilloscope was used [11]. Cheng-Kuang Yang has used a LeCroy 422 \& 200 $\mathrm{MHz}$ two-channel digital storage oscilloscope for measurement of the current signal and discharge frequency in ECDM machining process [4].

\section{Optical Microscope}

A. Kulkarni et al. have taken borosilicate glass used as the material to be machined. For surface feature analysis, it is used under such condition of no discharge striking the work-piece surface. The optical microscope was used for analyzing surface feature of machined area with the respective parameters of copper \& Tantalum tool material, voltage, concentration of the electrolyte under magnification of 100X \& 200X shown in Fig. 9 [12]. C. T. Yang et al.

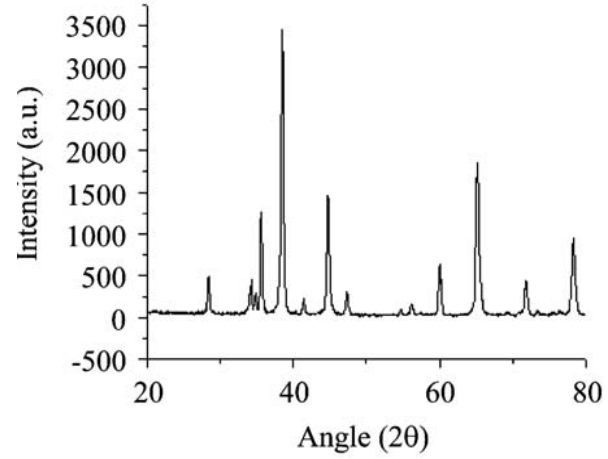

Fig. 7 The XRD patterns obtained for ECDM specimen.

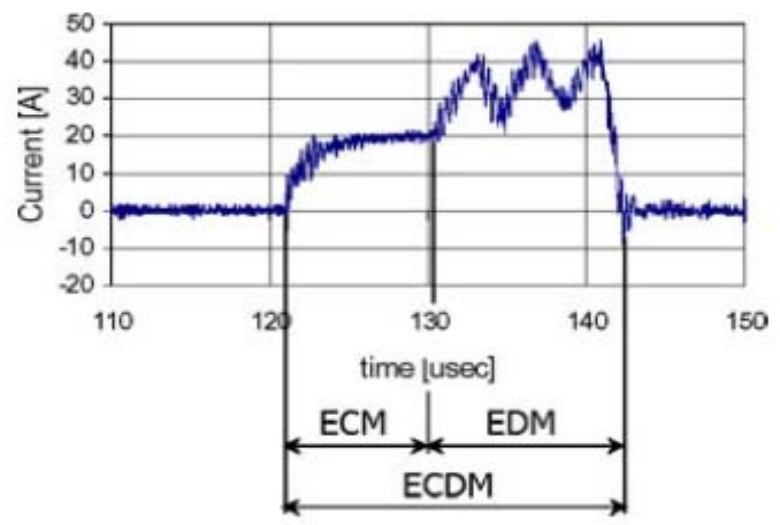

Fig. 8 Voltage and current waveforms during ECDM.

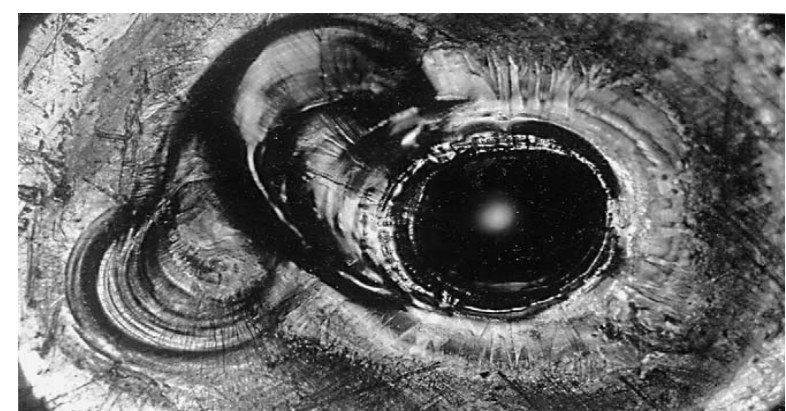

Fig. 9 Optical photograph showing discharge affected region with ring patterns and metal removal.

have obtained groove shapes using different work-piece feeding mechanism, discharge the current response, different electrolytes such as $\mathrm{NaOH} \& \mathrm{KOH}$ were used. Optical microscope micrographs were used for analyzing surface structure [5].

\section{AFM (Atomic Force Microscopy)}

A. Ravi Sankar et al. have measured surface roughness of coupled effects of an electroplated gold layer plate using AFM, this plate is further used for micomachined by using ECDM process. The 
deposition rate and the mean surface roughness of the plated gold layer of thickness around $20 \mu \mathrm{m}$ were found to be around $6.5 \mu \mathrm{m} / \mathrm{h}$ and $2 \mathrm{~nm}$ respectively at a current density of $3.5 \mathrm{~mA} / \mathrm{cm}^{2}$ shown in Fig. 10 [2].

\section{Digital Microscope}

M. Coteata et al. have used digital microscope for measurement of micro-cavities observed on the lateral side of the electrode. The initial diameter of the electrode tool was $0.5 \mathrm{~mm}$ and measuring tool wear of the electrode after machining process is shown in Fig. 11 [13].

\section{Surface Topography}

M. Schopf et al. have found out the efficiency and accuracy of new ECDM technology i.e., ECDM trueing and dressing. Surface quality and roundness of grinding wheel \& work-pieces are analyzed. For measurement of surface topography of metal bonded grinding wheel D46 C75 used a tactile surface measuring instrument Form Talysurf Series 2 of Taylor Hobson was used as shown in Fig.12 [9].

\section{Pyrometer}

Anjali V. Kulkarni has measured during ECDM

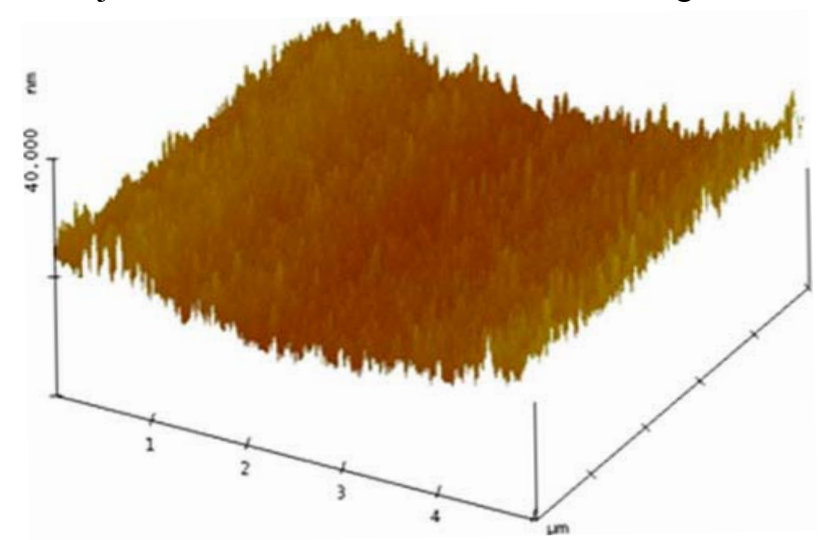

Fig. 10 An AFM photograph of surface roughness of the electroplated gold layer at a current density of $3.5 \mathrm{~mA} / \mathrm{cm}^{2}$.

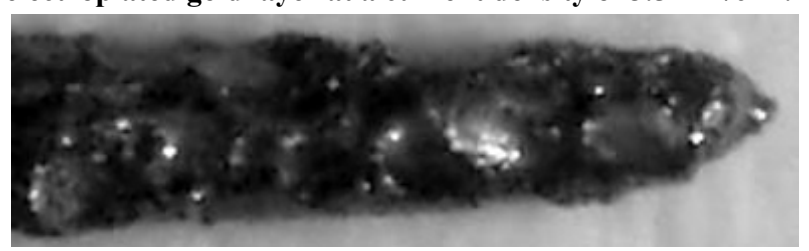

Fig. 11 Electrode tool wear after machining process.

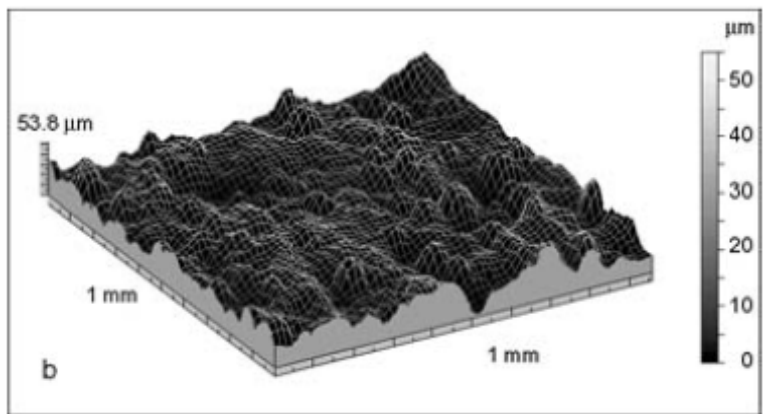

Fig. 12 Surface topography of a metal bonded grinding wheel D46 C75 ECDM trueing \& dressing-spacing $4 \mu \mathrm{m}$, measuring area $1 \times 1 \mathrm{~mm}$.

process there is producing high temperature to sense the high, transient temperature of the localized zone on the work-piece surface where discharge strikes, a pyrometer is used. For that purpose Pyrometer model D-7441, Kohelberg, with sensing temperature ranges of $815-1,700{ }^{\circ} \mathrm{C}$ measures the temperature in a non-intrusive way [11].

\section{Microbalance}

S. Tandon et al. Material removal from the work-piece and the tool was measured by a microbalance with accuracy of $1 \times 10^{-5} \mathrm{~g}$. In this case, work piece material was taken as glass-epoxy composite specimen [14].

\section{Conclusions}

(1) This paper shows that measuring equipments used in this machining process for analysis of output parameters;

(2) It shows that different equipment used for different purpose;

(3) Every measuring equipments show key role in analysis specially Scanning Electron Microscope gives the exact values of machined surface images in precise manner.

\section{Acknowledgments}

This paper is a revised and expanded version of a paper entitled "Measurement Analysis in Electrochemical Discharge Machining (ECDM) Process" presented as 4th National Conference on Advances in Metrology (AdMet) held during $25^{\text {th }}$ to 
$27^{\text {th }}$ February 2015 in CSIR-CMERI, Durgapur, India.

\section{References}

[1] Liu, J. W., Yue, T. M., and Guo, Z. N. 2010. “An Analysis of the Discharge Mechanism in Electrochemical Discharge Machining of Particulate Reinforced Metal Matrix Composites." International Journal of Machine Tools \& Manufacture 50: 86-96.

[2] Sankar R. A., Swathi, S. B. V., and Das, S. 2011. "Coupled Effects of Gold Electroplating and Electrochemical Discharge Machining Processes on the Performance Improvement of a Capacitive Accelerometer." Microsystem Technology 17: 1661-1670.

[3] Coteata, M., Schulze, H. P., and Slatineanu. L. 2011. "Drilling of Difficult-to-Cut Steel by Electrochemical Discharge Machining." Materials and Manufacturing Processes 26: 1466-1472. DOI:10.1080/10426914.2011.557286

[4] Yang, C. K., Wu, K. L., Hung, J. C., Lee, S. M., Lin, J. C., and Yan, B. H. 2011. "Enhancement of ECDM Efficiency and Accuracy by Spherical Tool Electrode." International Journal of Machine Tools \& Manufacture 51: 528-535.

[5] Yang, C. T., Song, S. L., Yan, B. H., and Huang, F. Y. 2006. "Improving Machining Performance of Wire Electrochemical Discharge Machining by Adding $\mathrm{SiC}$ Abrasive to Electrolyt." International Journal of Machine Tools \& Manufacture 46: 2044-2050.

[6] Jain, V. K., and Priyadarshini, D. 2013. "Fabrication of Micro Channels in Ceramics (Quartz) Using Electrochemical Spark Micro Machining (ECSM)." Proceedings of Global Engineering, Science and
Technology Conference 3-4 October Bay View Hotel, Singgpore.

[7] Zheng, Z. P., Wu, K. L, Hsu Y. S., Huang, F. Y., and Yan, B. H. 2007. "Feasibility of 3D Surface Machining on Pyrex Glass by Electrochemical Discharge Machining (ECDM)." Proc. AEMS07, 28-30.

[8] Liu, J. W., Yue, T. M., and Guo, Z. N. 2013. "Grinding-Aided Electrochemical Discharge Machining of Particulate Reinforced Metal Matrix Composites." International Journal of Advance Manufacturing Technology 68: 2349-2357.

[9] Schopf, M., Beltrami. I., Boccadoro, M., and Kramer, D. 2001. "ECDM (Electro Chemical Discharge Machining), a New Method for Trueing and Dressing of Metal Bonded Diamond Grinding Tool.” CIRP Annals-Manufacturing Technology 50 (1): 125-128.

[10] Raghuram, V., Tabeti. P., Srinivasa, Y. G., and Narayanasamy, K. 1995. "Effect of the Circuit Parameters on the Electrolyte in the Electrochemical Discharge Phenomenon." Journal of Materials Processing Technology 52: 301-318.

[11] Kulkarni, A. V. 2007. "Electrochemical Discharge Machining Process." Defence Science Journal 57: 765-770.

[12] Kulkarni, A., Sharan, R., and Lal, G. K. 2002. "An Experimental Study of Discharge Mechanism in Electrochemical Discharge Machining." International Journal of Machine Tools \& Manufacture 42: 1121-1127.

[13] Coteata, M., Slatineanu, L., Dodun, O., and Ciofu, C. 2008. "Electrochemical Discharge Machining of Small Diameter Holes." International Journal Material Form (2008) Suppl 1: 1327-1330.

[14] Tandon, S., Jain, V. K., Kumar, P., and Rajurkar, K. P. 1990. "Investigations into Machining of Composites." Precision Engineering 12: 4. 